\title{
HUBUNGAN EKSTRAKULIKULER PASKIBRA DENGAN SIKAP NASIONALISME PESERTA DIDIK DI SMAN 1 BANJARBARU
}

Pembimbing Akademik : Dra. Hj. Rochgiyanti, M.Si., M.Pd Proposal Skripsi

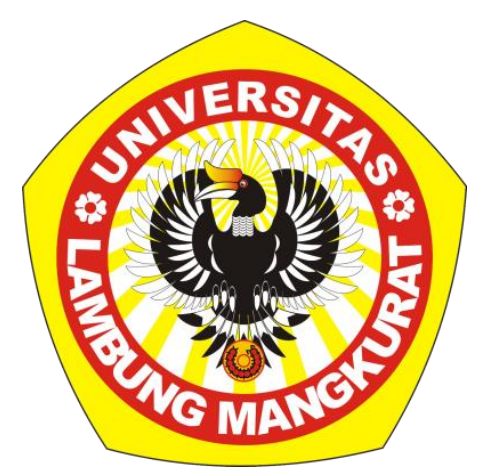

Oleh:

PISSYA SEKAR SARI DAMHUDIE 1710111120015

PROGRAM STUDI PENDIDIKAN SEJARAH JURUSAN PENDIDIKAN ILMU PENGETAHUAN SOSIAL FAKULTAS KEGURUAN DAN ILMU PENDIDIKAN UNIVERSITAS LAMBUNG MANGKURAT BANJARMASIN 2020 


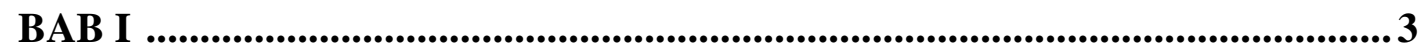

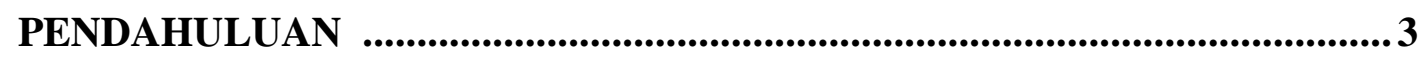

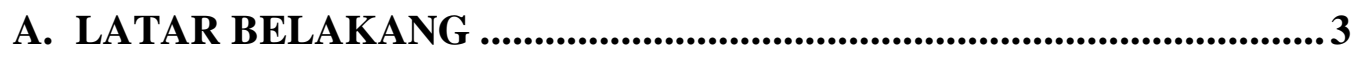

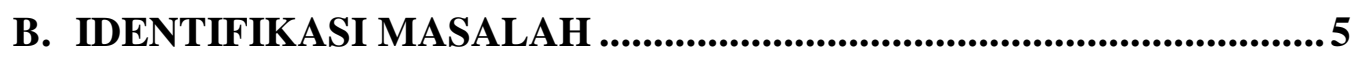

C. PEMBATASAN MASALAH ...........................................................5

D. RUMUSAN MASALAH...............................................................5

E. TUJUAN MASALAH.....................................................................6

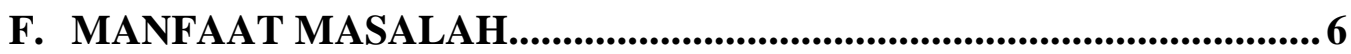

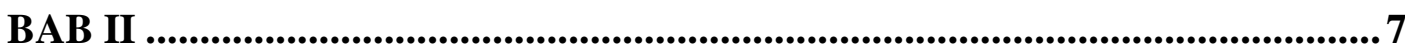

KAJIAN TEORI, KERANGKA BERFIKIR DAN HIPOTESIS........................ 7

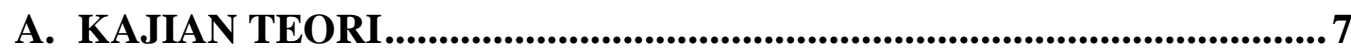

B. HASIL PENELITIAN YANG RELEVAN ........................................9

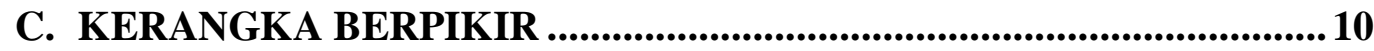

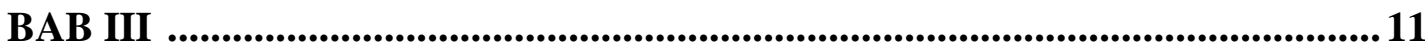

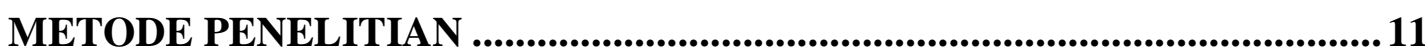

A. TEMPAT DAN WAKTU PENELITIAN ...........................................11

B. JENIS PENELITIAN ........................................................................11

C. DATA DAN SUMBER DATA ..........................................................11

D. TEKNIK PENGUMPULAN DATA ...................................................11

E. TEKNIK PEMERIKSAAN KEABSAHAN DATA...............................12

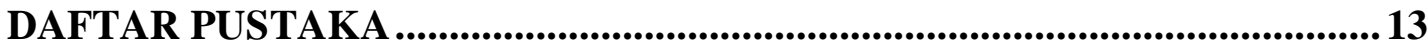




\section{BAB I}

PENDAHULUAN

\section{A. LATAR BELAKANG MASALAH}

Pendidikan adalah suatu kegiatan yang dilakukan secara sadar dan sistematis dalam mengembangkan potensi peserta didik. Selain itu Pendidikan juga merupakan suatu hal yang menjadi kebutuhan setiap manusia karena tanpa adanya pendidikan manusia akan kesulitan dalam mengikuti perkembangan. Pendidikan dapat berupa proses pembelajaran pengetahuan, keterampilan, dan kebiasaan.

Pendidikan menurut Ki Hajar Dewantara adalah suatu tuntutan di dalam hidup tumbuhnya anak-anak. Maksudnya ialah bahwa pendidikan menuntun segala kekuatan kodrat yang ada pada peserta didik agar sebagai manusia dan anggota masyarakat dapat mencapai keselamatan dan kebahagiaan hidup yang setinggi-tingginya.

Pendidikan karakter dalam kurikulum 2013 bertujuan sebagai peningkat mutu proses dan hasil pendidikan, yang mengarah pada pembentukan akhlak dan budi pekerti peserta didik secara seimbang sesuai dengan Standar Kompetensi Lulusan pada setiap satuan pendidikan. Melalui implementasi Kurikulum 2013 ini peserta didik diharapkan mampu meningkatkan nilai-nilai karakter dan akhlak mulia sehingga terwujud dalam kegiatan sehari-hari.

Sesuai dengan tujuan Presiden tentang penguatan karakter penerus bangsa yang diimplementasikan oleh Kementerian Pendidikan dan Kebudayaan melalui gerakan Penguatan Pendidikan Karakter (PPK) yang digulirkan sejak tahun 2016. Bukan hanya literasi yang dijadikan fokus pendidikan pada masa ini namun PPK juga menjadi pendorong agar pendidikan nasional kembali diperhatikan melalui empat dimensi pendidikan yakni Integrasi, Intrakulikuler, Kokurikuler dan Ekstrakulikuler.

Kegiatan Intrakulikuler adalah program utama dalam mendidik peserta didik yang dilakukan oleh pihak sekolah dengan kegiatan belajar mengajar yang teratur, jelas dan terjadwal. Kegitan Kokurikuler adalah kegiatan pendalaman materi pembelajaran yang telah dipelajari dalam kegiatan Intrkulikuler. Kegiatan Ekstrakulikuler merupakan kegiatan kulikuler yang dilaksanakan peserta didik diluar dari jam kegiatan intrakulikuler dan kegiatan kokulikuler dibawah bimbingan dan pengawasan sekolah. 
Kegiatan ekstrakulikuler merupakan salah satu sarana yang mampu Pembina karakter peserta didik salah satunya sikap nasionalisme. Kegiatan ekstrakulikuler juga memiliki tujuan yang sama dengan pendidikan nasional, yaitu membentuk karakter peserta didik. Tujuan ekstrakulikuler tertera pada Permendikbud RI No. 62 tahun 2014 tentang kegiatan ekstrakulikuler pada pendidikan dasar dan pendidikan menengah pasal 2 yang menyatakan bahwa kegiatan ekstrakulikuler dilakukan dengan tujuan mengembangkan potensi, bakat, minat, kemampuan, kepribadian, kerjasama dan kemandirian peserta didik dalam rangka mendukung pencapaian tujuan pendidikan nasional.

Nilai karakter Nasionalis adalah cara bersikap, berbuat serta berpikir yang mengarah kepada kesetiaan, kepedulian dan penghargaan yang tinggi terhadap bahasa, lingkungan fisik, social, budaya, ekonomi, dan politik bangsa, menempatkan kepentingan bangsa dan negara di atas kepentingan diri dan kelompoknya. Namun, seiring perkembangan zaman, sikap nasionalisme dikalangan pemuda kian memudar.

SMA Negeri 1 Banjarbaru adalah salah satu Sekolah Menengah Atas Negeri yang ada di Provinsi Kalimantan Selatan lebih tepatnya berada di Kota Banjarbaru. SMA Negeri 1 Banjabaru beralamatkan di Jalan Keruing No 3 RT. 1 RW.1 Kelurahan Kemuning Kecamatan Banjarbaru Selatan Kota Banjarbaru Provinsi Kalimantan Selatan. Sama seperti SMA pada umumnya lembaga ini juga memiliki dan menjalankan berbagai macam kegiatan ekstrakulikuler yang diantaranya yaitu ekstrakulikuler Pasukan Pengibar Bendera (PASKIBRA), Palang Merah Remaja (PMR), Praja Muda Karana (PRAMUKA), Volley Ball, Basket dan Theater.

Keputusan Menteri Pendidikan dan Kebudayaan No. 0416/U/1984 mengungkapkan pendidikan pendahuluan bela Negara yang diselenggarakan sekolah antara lain dengan pembentukan pasukan pengibar bendera (PASKIBRA) sekolah. Beberapa jenis kegiatan dalam ekstrakulikuler paskibra yaitu Peratuan Baris Berbaris (PBB), Tata Upacara Bendera (TUB) serta Latihan Dasar Kepemimpinan Siswa (LDKS).

Pada jurnal penelitian Sakinah Meindahsari Sutipto yang berjudul "Pelaksanaan Ekstrakulikuler Paskibra dalam Upaya Menumbuhkan Sikap Nasionalisme siswa di SMP Negeri 3 Malang" menunjukkan bahwa hasil penelitian kegiatan ekstrakulikuler paskibra memberikan pengaruh terhadap pembentukan karakter dan sikap siswa karena paskibra dapat menambahkan sikap tegas, 
bertanggungjawab, disiplin, percaya diri dan memiliki jiwa kepemimpinan, serta di dalam setiap pelaksanaan program kegiatan ekstrakulikuler paskibra dapat menumbuhkan aspek sikap nasionalisme yakni cinta tanah air, rela berkorban, persatuan dan kesatuan, serta jiwa pembaharuan atau pantang menyerah.

Berdasarkan uraian latar belakang di atas, yang mana peneliti mempunyai keinginan untuk mengetahui peran dari kegiatan ekstrakulikuler paskibra yang diharapkan mampu mengarahkan pembentukan sikap nasionalisme sebagai pembentuk karakter peserta didik di SMA Negeri 1 Banjarbaru. Maka peneliti tertarik untuk mengadakan penelitian yang berjudul "Hubungan Ekstrakulikuler Paskibra Dengan Sikap Nasionalisme Peserta Didik di SMA Negeri 1 Banjarbaru"

\section{B. IDENTIFIKASI MASALAH}

Berdasarkan latar belakang yang sudah diuraikan di atas, maka dapat diidentifikasi permasalahan dari penelitian ini adalah sebagai berikut:

1. Kurangnya sikap nasionalisme peserta didik

2. Pelaksanaan penanaman sikap nasionalisme tidak bejalan dengan optimal

3. Menurutnya karakter semangat kebangsaan peserta didik dengan ditandai masih ada yang tidak bersungguh-sungguh saat upacara

4. Menurunnya karakter cinta tanah air dengan dengan ditandai lebih mencintai budaya luar

\section{PEMBATASAN MASALAH}

Mengingat pembahasan yang dipaparkan dalam penelitian ini mengenai sikap nasionalisme, maka diperlukan adanya fokus penelitian. Dalam penelitian kali ini permasalahan yang akan dibahas hanya mengenai hubungan ekstrakulikuler paskibra dengan sikap nasionalisme peserta didik khususnya pada peserta didik SMAN 1 Banjarbaru. Pembatasan masalah ini dilakukan agar penelitian lebih terfokus dan mendapatkan hasil yang optimal.

\section{RUMUSAN MASALAH}

Dilihat dari batasan masalah di atas, maka peneliti dapat merumuskan permasalahan yaitu 
1. Bagaimana hubungan ekstrakulikuler paskibra dengan sikap nasionalisme peserta didik di SMAN 1 Banjarbaru?

\section{E. TUJUAN MASALAH}

Berdasarkan rumusan masalah di atas, maka tujuan penelitian ini yaitu untuk mengetahui hubungan ekstrakulikuler paskibra dengan sikap nasionalisme peserta didik di SMAN 1 Banjarbaru.

\section{F. MANFAAT MASALAH}

Manfaat dari penelitian yang akan dilaksanakan di SMAN 1 Banjarbaru ini diantaranya sebagai berikut:

\section{Secara Teoritis}

Secara teoritis, penelitian ini dapat dijadikan sebagai referensi tambahan bagi praktisi pendidikan yang akan mengadakan perbaikan penanaman sikap nasionalisme peserta didik melalui ekstrakulikuler paskira, khususnya pada peserta didik di SMAN 1 Banjarbaru.

\section{Secara Praktis}

a. Bagi penulis, untuk dapat menambah pengetahuan dan dapat mengembangkan ilmu yang diperoleh selama menjalani kuliah sebagai bekal dikemudian hari.

b. Bagi pihak sekolah, hasil penelitian ini dapat dijadikan sebagai masukan dalam rangka penanaman sikap nasionalisme kepada peserta didik melalui ekstrakulikuler paskibra di SMAN 1 Banjarbaru.

c. Bagi guru, penelitian ini dapat memberikan informasi tambahan dan pengetahuan dalam mengintegrasikan sikap nasionalisme pada kegiatan ektrakulikuler paskibra di SMAN 1 Banjarbaru.

d. Bagi peserta didik, untuk dapat menambah pengetahuan peserta didik tentang hubungan ekstrakulikuler paskibra dengan sikap nasionalisme peserta didik, sehingga dapat mengambil hal positif dari kegiatan estrakulikuler paskibra yang memiliki kaitan dan dampak pada sikap nasionalisme. 


\section{BAB II \\ KAJIAN TEORI, KERANGKA BERFIKIR DAN HIPOTESIS}

\section{A. KAJIAN TEORI}

\section{Pengertian Karakter}

Menurut Kamus Besar Bahasa Indonesia Kementrian Pendidikan dan Kebudayaan Republik Indonesia kata karakter berarti sifat-sifat kejiwaan, akhlak atau budi pekerti yang membedakan seseorang dengan yang lain, tabiat atau watak.

Menurut Heri Gunawan Karakter adalah keadan asli yang ada dalam diri individu seseorang yang membedakannya antara diri sendiri dan dengan orang lain.

Dari beberapa pendapat diatas maka dapat disimpulkan bahwa karakter merupakan sebuah sifat, watak, tabiat seseorang yang ada dalam dirinya dan perilaku yang diterapkan dalam kehidupan sehari-hari baik dalam bertindak dan bersikap dalam melakukan sesuatu dan mengambil langkah.

\section{Pendidikan Karakter}

Menurut Heri Susanto pendidikan karakter dapat terjadi di dalam maupun diluar kelas. Dapat pula disimpulkan bahwa Pendidikan karakter adalah sebuah usaha lembaga pendidikan baik sengaja atau tidak dalam memberikan penanaman nilai karakter kepada peserta didik ataupun warga sekolah melalui kegiatan yang ada di sekolah seperti kegiatan belajar mengajar, kegiatan kokulikuler dan kegiatan ekstrakulikuler.

\section{Pengertian Nasionalisme}

Jika ditinjau secara etimologis nasionalisme berasal dari bahasa latin Nation yang berarti bangsa yang dipersatukan. Menurut Sunarso dkk (2008;36) nasionalisme adalah sikap nasional untuk mempertahankan kemerdekaan dan harga diri bangsa dan sekaligus menghormati bangsa lain. Istilah nasionalisme pertama kali digunakan di Jerman pada abad ke- 15 oleh mahasiswa yang dating dari daerah yang sama atau berbahasa sama. Kata tersebut untuk menunjukkan perasaan cinta mereka terhadap bangsa/suku asal mereka ( Ritter dalam Adisusilo, 2012:73 ). Dengan demikian, penggunaan istilah nasionalisme adalah sebagai representasi perasaan cinta seseorang terhadap bangsa, bahasa dan daerah asal mereka.

Penggunaan istilah nasionalisme dalam perkembangannya mengalami perubahan, dimana sejak revolusi Perancis meletus pada tahun 1789. Sejak saat itu, 
istilah nasionalisme menjadi label perjuangan di Negara-negara Asia-Afrika yang dijajah bangsa Barat.

Berdasarkan penjabaran di atas, nasionalisme dalam sejarah digunakan untuk beberapa hal, yaitu:

1. Untuk mewakilkan perasaan rasa cinta terhadap tanah air, ras, bahasa dan budaya, maka dalam hal ini nasionalisme sama dengan patriotisme.

2. Sebagai representasi suatu keinginan akan kemerdekaan politik dan keselamatan bangsa.

3. Sebagai doktrin yang menyatakan bahwa bangsanya sendiri harus dominan atau tertinggi di antara bangsa-bangsa lain dan harus bertindak agresif.

Heri Susanto (2014:52) menegaskan, "Penggunaan konsep psikologis dalam penanaman nilai nasionalisme ini berangkat dari kenyataan bahwa siswa dalam tiap perkembangannya memerlukan perlakuan yang berbeda karena adanya perbedaan tingkat kematangan psikologis. Satu hal yang harus dipahami oleh guru adalah bahwa siswa-siswa kita adalah entitas biologis yang melekat padanya komponen psikologis, spiritual, dan emosional. Dengan demikian sangatlah penting juga untuk mempertimbangkan berbagai factor tersebut dalam pembelajaran."

Jika pada intinya sikap nasionalisme dapat diartikan sebagai sikap untuk mempertahankan harga diri dan kehormatan suatu bangsa, sehingga akan muncul perasaan satu sebagai suatu bangsa, satu dengan seluruh warga yang ada dalam masyarakat. Nasionalisme juga dapat diartikan sebagai suatu orientasi pemikiran yang dapat dipakai untuk mempertahankan serta menanggulangi segala tantangan dan kesulitan yang dihadapi bangsa pada saat ini atau masa yang akan datang. Dengan sikap kebangsaan yang harus dibangun kembali pada saat ini perlu dilandasi dengan persepsi dan konsepsi nasionalisme baru dan juga pemahaman terhadap konsep ikatan bangsa itu sendiri yang berwawasan social, budaya dan ekonomi.

\section{Pengertian Ekstrakulikuler Paskibra}

Ektrakulikuler merupakan kegiatan kulikuler yang dilakukan oleh peserta didik di luar dari kegiatan intrakulikuler dan kegiatan kokulikulerm, kegiatan ini masih di dalam pengawasan sekolah yang memiliki tujuan untuk mengembangkan potensi dan bakat peserta didik.

Kegiatan ekstrakulikuler terbagi menjadi dua, yakni 
1. Kegiatan ekstrakulikuler wajib yang merupakan kegiatan ekstrakulikuler yang wajib diadakan oleh sekolah dan diikuti oleh seluruh peserta didik.

2. Kegiatan ekstrakulikuler pilihan yang merupakan kegiatan ekstrakulikuler yang dikembangkan oleh sekolah dan dapat diikuti oleh peserta didik sesuai dengan minat masing-masing.

3. Kegiatan Ekstrakulikuler Paskibra merupakan kegiatan yang bertujuan untuk menanamkan sikap cinta tanah air dan semangat berkebangsaan. Paskibra merupakan pasukan pengibar bendera yang bertugas melakukan pengibaran dan penurunan bendera merah putih di ruang lingkup sekolah. Ada beberapa kegiatan yang dipelajari dalam ekstrakulikuler paskibra antara lain PBB, langkah dan cara pengibaran dan penurunan bendera (TUB) pada setiap upacara bendera yang dilakukan secara rutin di sekolah.

\section{B. HASIL PENELITIAN YANG RELEVAN}

1. Penelitian yang dilakukan oleh Fajar Kawentar pada tahun 2015 yang berjudul "Pelaksanaan Penanaman Nilai Nasionalisme di SD Negeri II Klaten"

2. Penelitian yang dilakukan oleh Achmad Susanto pada tahun 2018 yang berjudul "Studi Tentang Integritas Nilai-Nilai Nasionalisme dalam Pembelajaran PPKN di SMP Negeri 1 Bandar Sribhawono Lampung Timur“"

3. Penelitian yang dilakukan oleh Firman Yusup pada tahun 2011 yang berjudul "Penanaman Nilai-Nilai Nasionalisme dalam Lingkup Kehidupan Sehari-Hari Di Pondok Pesantren Darul Falah Desa Jekulo Kecamatan Jekulo Kabupaten Kudus “

4. Penelitian yang dilakukan oleh Sakinah Meindahsari Suripto pada tahun 2014 yang berjudul "Pelaksanaan Ekstrakulikuler Paskibra dalam Upaya Menumbuhkan Sikap Nasionalisme siswa di SMP Negeri Malang”

5. Penelitian yang dilakukan oleh Chanda Anry Lestari pada tahun 2020 yang berujudul "Pengaruh Kegiatan Ekstrakulikuler Paskibra Terhadap Pembentukan Karakter Siswa MA Al-Awwabin Tahun 2018/2019” 


\section{KERANGKA BERPIKIR}

Karakter terbentuk melalui beberapa faktor diantaranya ada faktor internal dan faktor eksternal. Faktor internal terbentuk dari nurani, adat, kebiasaan, kemauan dan suara hati. Sedangkan faktor eksternal terbentuk dari lingkungan dan pendidikan.

Pendidikan merupakan faktor eksternal dalam pembentukan karakter peserta didik. Didalam system pendidikan terdapat kurikulum, dimana kurikulum tersebut terbagi menjadi tiga program pendidikan, yang diantaranya ialah kegiatan intrakulikuler, kegiatan kokulikuler, dan kegiatan ekstrakulikuler.

Kegiatan ekstrakulikuler yang ada di sekolah menjadi salah satu sarana yang dapat membina dan membentuk karakter peserta didik. Paskibra adalah salah satu kegiatan ekstrakulikuler yang memiliki kegiatan Peraturan Baris Berbaris (PBB), Tata Upacara Bendera (TUB) dan Latihan dasar Kepemimpinan Siswa (LDKS) yang mana kegiatan ini dapat membentuk karakter peserta didik .

\section{Gambar 1.1 Kerangka Berpikir di dalam Penelitian}
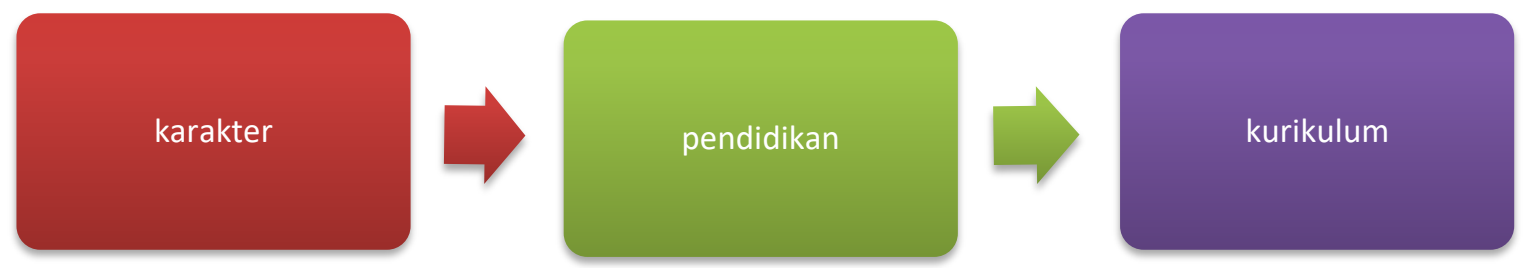

hubungan esktrakulikuler paskibra dengan sikap nasionalisme peserta 


\section{BAB III \\ METODE PENELITIAN}

\section{A. TEMPAT DAN WAKTU PENELITIAN}

Tempat penelitian ini di lakukan di SMA Negeri 1 Banjarbaru yang beralamat di Jalan Keruing No 3 Banjarbaru Kalimantan Selatan. Waktu Pelaksanaan Penelitian ini adalah pada bulan Oktober 2020.

\section{B. JENIS PENELITIAN}

Penelitian Kuantitatif

\section{DATA DAN SUMBER DATA}

Adapun yang menjadi subjek dalam penelitian ini yaitu Peserta didik di SMA Negeri 1 Banjarbaru.

\section{TEKNIK PENGUMPULAN DATA}

Dalam penelitian ini, teknik pengumpulan data yang digunakan adalah sebagai berikut :

\section{Kuesioner ( Angket )}

Teknik kuesioner adalah teknik pengumpulan data yang dilakukan dengan cara memberikan beberapa pertanyaan dan pernyataan tertulis yang akan dijawab oleh responden. Kuesioner disusun berdasarkan dari variable yang sudah ditentukan oleh peneliti. Dalam membuat kuesioner ini, peneliti menggunakan alat ukur berupa skala likert untuk mrngkuantifikasikan hasil jawaban dari responden.

Tabel 3.1 Skor Alternatif Jawaban Responden

\begin{tabular}{|c|c|}
\hline Alternatif Jawaban & Skor Pertanyaan \\
\cline { 2 - 2 } & Positif \\
\hline Sangat Setuju & 5 \\
\hline Setuju & 4 \\
\hline Ragu-ragu & 3 \\
\hline Tidak setuju & 2 \\
\hline Sangat Tidak Setuju & 1 \\
\hline
\end{tabular}




\section{Dokumentasi}

Dokumentasi merupakan informasi berupa catatan penting yang digunakan sebagai pelengkap data dalam penyusunan penelitian. Dokumentasi dalam penelitian ini berupa data peserta didik yang mengikuti ekstrakulikuler paskib dan dokumen program kerja kegiatan ekstrakulikuler paskib.

\section{Wawancara}

Wawancara merupakan teknik pengumpulan data yang dilakukan secara langsung berhadapan dengan responden guna untuk mengetahui permasalahan yang terjadi terutama yang berkaitan dengan hubungan ekstrakulikuler paskib dengan sikap nasionalisme peserta didik.

\section{Observasi}

Melalui observasi peneliti dapat langsung mengamati kegiatan ekstrakulikuler paskib sehingga dapat lebih mudah memahami kondisi kegiatan di lapangan.

\section{E. TEKNIK PEMERIKSAAN KEABSAHAN DATA}

\section{Uji Validitas}

Validitas merupakan suatu ukuran yang digunakan untuk menunjukkan tingkat kevalidan atau kesahan suatu instrument penelitian. Instrument dinyatakan valid jika bernilai 0,3 atau lebih. Uji validitas instrument biasa digunakan untuk mengetahui apakah masing-masing butir soal pertanyaan valid atau tidak valid.

\section{Uji Reliabilitas}

Reliabilitas merupakan instumen yang bertujuan datanya dapat dipercaya dan datanya memang benar sesuai dengan kenyatanyaan, maka uji ini akan beberapa kali diambil dengan hasil yang akan tetap sama. 


\section{DAFTAR PUSTAKA}

\section{BUKU}

Susanto, H. (2014). Seputar Pembelajaran Sejarah. Banjarmasin: Aswaja Pressindo.

Salahudim. A dan Irwanto Alkrienciehie. (2013). Pendidikan karakter: Pendidikan berbasis agama \&budaya bangsa.Bandung: Pustaka Setia.

Kemendiknas. (2011). Panduan Pelaksanaan Pendidikan Karakter. Jakarta: Badan Penelitian dan Pengembangan Pusat Kurikulum dan Perbukuan,

Gunawan, Heri. (2012) Pendidikan Karakter: Konsep dan Implementasi, Bandung: Alfabeta.

\section{SKRIPSI DAN JURNAL}

Suripto, Sakinah Meindahsari. "Pelaksanaan Ekstrakurikuler Paskibra (Pasukan Pengibar Bendera) dalam Upaya Menumbuhkan Sikap Nasionalisme siswa di SMP Negeri Malang". Jurnal Online pada Universitas Negeri Malang Jurusan Hukum dan Kewarganegaraan, 2014.

Lestari, Chanda Anry "Pengaruh Kegiatan Ekstrakulikuler Paskibra Terhadap Pembentukan Karakter Siswa MA Al-Awwabin Tahun 2018/2019”. Jurnal Online pada Universitas Negeri Islam Jakarta. 2020.

\section{UNDANG-UNDANG}

Peraturan Menteri Pendidikan dan Kebudayaan RI No.62 Tahun 2014 tentang Kegiatan ekstrakurikuler pada Pendidikan Dasar dan Pendidikan Menengah. Jakarta: Mendikbud

\section{INTERNET}

KBBI Daring. "Karakter". diakses pada 20 Maret 2020. (http://kbbi.kemendikbud.go.id/enteri/karakter) 